\title{
Critical points in ecosystem responses to fishing and environmental pressures
}

\author{
Scott I. Large ${ }^{1,3, *}$, Gavin Fay ${ }^{1,4}$, Kevin D. Friedland ${ }^{2}$, Jason S. Link ${ }^{1}$ \\ ${ }^{1}$ NOAA-Fisheries, 166 Water Street, Woods Hole, MA 02543, USA \\ ${ }^{2}$ NOAA, National Marine Fisheries Service, 28 Tarzwell Drive, Narragansett, RI 02882, USA \\ ${ }^{3}$ Present address: International Council for the Exploration of the Sea (ICES), Copenhagen V 1553, Denmark \\ ${ }^{4}$ Present address: School for Marine Science and Technology, University of Massachusetts Dartmouth, Fairhaven, MA 02719, USA
}

ABSTRACT: Ecosystem dynamics are often influenced by both environmental and anthropogenic pressures. Increased demand for living marine resources has resulted in global declines of targeted species, which are often managed under a single-species paradigm that does not fully incorporate ecosystem considerations such as ecological interactions or environmental factors. Ecosystem-based fisheries management (EBFM) is a more holistic approach that concurrently addresses human, ecological, and environmental factors influencing living marine resources and evaluates these considerations collectively on a system level. For EBFM, reference points associated with management action need to be quantified. Methods have been developed to assign decision criteria to ecological indicators' response to human-use pressures, yet few efforts have established decision criteria in response to the combined influence of humanuse and environmental pressures. We translated ecological indicator response into a surface dependent on both fishing and environmental pressures. Using generalized additive models, we empirically determined critical points at which a small change in fishing and environmental pressure results in an abrupt change in ecosystem status. For the Northeast United States Shelf Large Marine Ecosystem, we identified critical points in ecological indicators that represent system production, size distribution, community structure, and ecosystem functioning. Our findings highlight the need to include both anthropogenic and environmental pressures for delineation of ecosystem decision criteria.

KEY WORDS: Reference points $\cdot$ Ecosystem-based fisheries management · EBFM · Thresholds · GAM · Dynamic factor analysis $\cdot$ DynFA

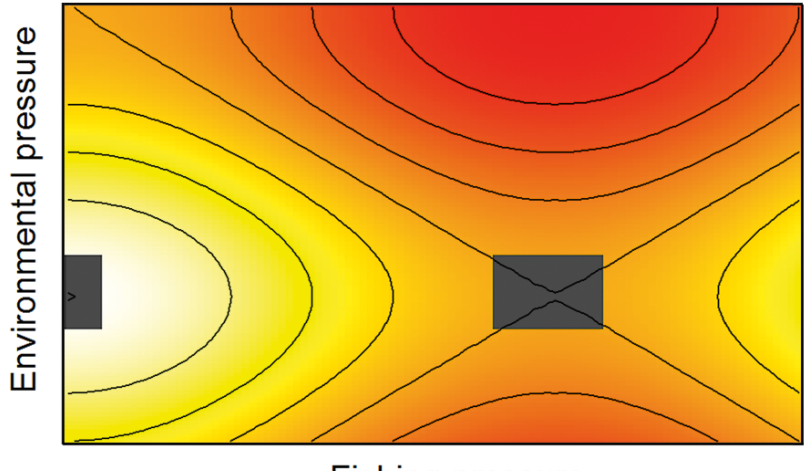

Fishing pressure

Critical points (gray polygons) quantified on a surface of ecosystem response dependent upon fishing and environmental pressures.

Image: S. I. Large

\section{INTRODUCTION}

In applied ecology, a suite of factors influence ecosystem dynamics, including environmental and anthropogenic stressors, which can alter the structure and functioning of ecosystems and ultimately have direct implications on management actions designed to conserve these systems (Christensen et al. 1996). Ecosystem-based management (EBM) is a living-resource management approach that is holistic in nature and incorporates multiple human uses and ecosystem processes (Christensen et al. 1996). Implementing EBM is not trivial, and like any complex system of decision making, it requires the development of goals, relevant ecosystem assessments, and deci- 
sion criteria for management action (Lackey 1998). EBM has been successfully implemented in terrestrial and aquatic (including marine) ecosystems with varied management goals. Examples where both environmental and anthropogenic factors influence the goods and services provided by their ecosystem include forests altered by fire suppression and logging (Allen et al. 2002) and lotic ecosystems altered by natural variability in flow regimes and obstructed flow caused by dams (Richter et al. 2003). Marine ecosystems are also influenced by natural environmental variability (Beaugrand et al. 2008) and multiple human uses, such as coastal-zone development and the harvest of living marine resources (LMRs; Pauly et al. 1998, Hsieh et al. 2006); however, innate difficulties associated with environmental and ecological sampling create special challenges for implementing marine EBM.

Increased demand for LMRs has resulted in global declines in targeted species' abundance (Hsieh et al. 2006), shifts in biotic processes (Bianchi et al. 2000), and deteriorated fisheries status, impacts that are often exacerbated in a changing environment (Shin \& Shannon 2010, Shackell et al. 2012). Traditional single- and multiple-species management approaches often do not fully incorporate ecosystem considerations such as ecological interactions and environmental processes, nor account for the cumulative impacts on LMRs as an interconnected system (Link 2002, Pikitch et al. 2004). Ecosystem-based fisheries management (EBFM) attempts to simultaneously address the effects of human, ecological, and environmental factors that influence LMRs and evaluate these considerations systemically (Larkin 1996).

Implementing EBFM follows the same steps as EBM: pre-defined management goals, an assessment of ecosystem status, and decision criteria to achieve management objectives (Sainsbury et al. 2000). Single-species fisheries management approaches often use decision criteria based on the response of population-level attributes to human-induced pressures (Hilborn \& Walters 1992). Analogous to traditional decision criteria, ecological indicators are synthetic and quantifiable attributes that represent ecosystem status and can also be translated into decision criteria for EBFM (Murawski 2000, Rice 2000, Trenkel \& Rochet 2003, Jennings 2005, Link 2005). Many ecological indicators have been suggested, and representative indicators have been vetted for routine monitoring of ecosystem status (Link \& Brodziak 2002, Link et al. 2002, Link 2005, Methratta \& Link 2006, Shin et al. 2010, Shackell et al. 2012).

Translating ecological indicators into decision cri- teria requires an understanding of ecological thresholds, which occur when a small change in a pressure results in either a large response or an abrupt change in ecosystem state or function (Groffman et al. 2006, Rice 2009). Mathematically, pressureresponse thresholds occur (1) when the second derivative of a function is equal to 0 and the first derivative is non-0 or (2) when the second derivative of a function crosses 0 , denoting a change in the magnitude or direction (e.g. from concave-up to concave-down) of the function, respectively. Both types of thresholds can be calculated from known functional forms such as piecewise regression models (Samhouri et al. 2010), or estimated from generalized additive models using finite differences (Fewster et al. 2000, Large et al. 2013).

Ecological thresholds have been theoretically and empirically evaluated in response to fishing and environmental pressure (Link 2005, Samhouri et al. 2010, Large et al. 2013). These simple pressure-response relationships may be useful for establishing decision criteria; however, they do not fully account for the combined effect of multiple pressures that concurrently influence ecosystem state (Jennings 2005, Fay et al. 2013, Large et al. 2013). Pressure-response thresholds can be extended into multivariate space by translating ecological indicator response into a surface dependent on both fishing and environmental pressures. The Northeast United States Shelf Large Marine Ecosystem (NES LME) is an ideal ecosystem to evaluate 2 covariate ecological thresholds because both human and environmental pressures have been linked to changes in ecosystem status (Shackell et al. 2012) and ecological and environmental sampling has been conducted regularly throughout the NES LME, resulting in long-term data (e.g. $>40$ yr) for ecological indicators and both fishing and environmental pressures (NEFC 1988, NEFSC 1998, Methratta \& Link 2006, EcoAP 2009, 2012).

Here, we propose a method to identify thresholds in past realized pressure-environment-state space that can be used to identify levels of multiple pressures where abrupt changes in the direction of ecosystem status likely happened. Critical points, or 2covariate thresholds, occur when the slopes of both pressure variables cross 0 and can be used to identify regions where the direction of indicator response changed as a result of both pressure variables. In a management context, critical points from multiple facets of ecosystem response to important sources of pressure can be integrated to provide advice and support towards delineating salient ecosystem reference points. 


\section{MATERIALS AND METHODS}

\section{Ecological indicators}

Data used in this study were compiled from the Northeast Fisheries Science Center surveys that monitor trends in abundance and distribution of important LMRs, as well as provide information regarding the ecology and oceanography of the NES LME region (Azarovitz 1981, NEFC 1988, NEFSC 1998). Since 1963, this scientific monitoring program has sampled 350 to 400 stations twice per year from Cape Hatteras (North Carolina, USA) to Nova Scotia (Canada) using a random stratified design. Stations within each depth-region stratum were randomly sampled, and surveyed fish or invertebrates were sorted by species, weighed, and their length was measured. Survey data were aggregated spatially and averaged across season to create a single time series for each indicator from 1964 to 2010 (Link et al. 2002). A suite of ecological indicators has been suggested and vetted as useful indicators for assessing ecosystem status for the NES LME (Link 2005, Methratta \& Link 2006, EcoAP 2009, 2012). These indicators represent key ecosystem processes such as energy flow, trophic dynamics, community structure, and size distribution (Table 1).

\section{Environmental pressures}

Environmental pressures influence circulation patterns, primary production, vertical mixing, and available nutrients across multiple geographic and temporal scales. Within the NES LME, we chose environmental pressures that influence ecosystem status and LMRs across the Atlantic basin, the NES LME, and regional portions of the

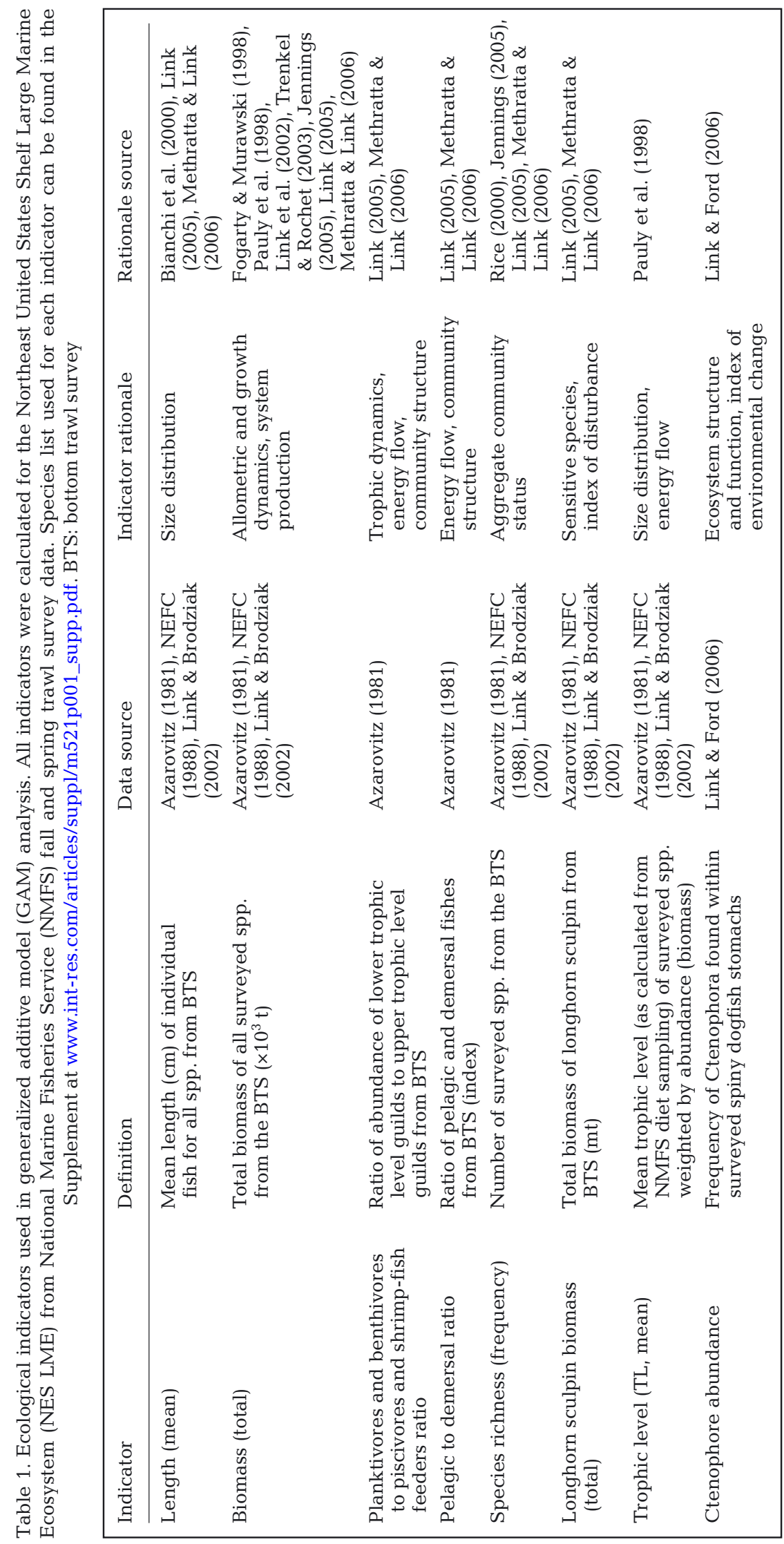


ecosystem. To facilitate analyses with ecological indicators, we averaged intra-annual measures to create a single annual time series for each pressure variable.

The Atlantic multidecadal oscillation (AMO) represents variance in thermohaline circulation patterns and was derived from sea surface temperature (SST; Enfield et al. 2001). The AMO index measures basinscale warm and cold phases in Atlantic SST, and has been related to hurricane activity and precipitation (1964-2010; data available at www.esrl.noaa.gov/ psd/data/correlation/amon.us.data) The North Atlantic oscillation (NAO) is also a basin-scale index that represents teleconnection patterns in the northern hemisphere and influences temperature, precipitation, and wind fields, which have been linked to key ecological processes in the North Atlantic (Stenseth et al. 2002). The NAO was calculated as the difference between the surface pressure of the subtropical (Azores) high and the Subpolar (Iceland) low (1964-2010; data available at https://climate dataguide.ucar.edu/sites/default/files/climate_index _files/nao_pc_annual.ascii; Hurrell 1995). The majority of NAO variance occurs during the winter months, so we also calculated the mean winter (December to February) NAO index (1964-2010; data available at https://climatedataguide.ucar.edu/sites/default/files/ climate_index_files/nao_pc_djf.ascii). SST influences species' distribution, growth, and many other ecological and biological processes. Monthly extendedrecord SSTs $\left({ }^{\circ} \mathrm{C}\right.$; ERSST v3b; Smith et al. 2008) were averaged across the NES LME into a single annual measurement from 1964 to 2010. Wind stress is a non-thermal regional physical pressure, which influences vertical mixing and horizontal currents. We calculated wind stress $\left(\mathrm{N} \mathrm{m}^{-2}\right.$; data obtained from NOAA's Environmental Research Division's Data Access Program) as the annual average of monthly mean wind stress for the NES LME from 1967 to 2010 (EcoAP 2012). Stratification influences the vertical distribution of nutrients and oxygen, and was measured as the vertical stacking of layers of water having different densities due to changes in temperature and salinity for the upper $50 \mathrm{~m}$ of the water column from 1977 to $2010\left(\mathrm{~kg} \mathrm{~m}^{-3} \mathrm{~m}^{-1}\right.$; EcoAP 2012). Gulf Stream north wall (GSNW) is the index of Gulf Stream position based on principal component analysis (PCA) of the latitude of the north wall at 6 longitudes $\left(79^{\circ}, 75^{\circ}, 72^{\circ}, 70^{\circ}, 67^{\circ}\right.$ and $\left.65^{\circ} \mathrm{W}\right)$ and influences vertical circulation and heat transport from tropics to higher latitudes (1966-2010; data available at www.pml-gulfstream.org.uk/data.htm; Taylor 1995).

\section{Human-use pressure}

Fishing pressure is influenced by both fishing effort and resource potential, such as the proportion of the community production available to harvest (Jennings 2005, Bundy et al. 2010). From an ecosystem perspective, fishing pressure is challenging to estimate, and the scientific community has yet to reach a consensus on the best practices to calculate ecosystem fishing pressure. One suggested measure of ecosystem fishing pressure is total reported landings over surveyed biomass (Shin et al. 2010); however, in our study, ecological indicators were also formulated with survey data, and including surveyed biomass in our estimate of fishing pressure could have been confounding. Therefore, we quantified fishing pressure as the total live weight of commercial species landings in the NES LME, calculated by aggregating data reported to the National Marine Fisheries Service (NMFS) by dealers at weigh-out, logbooks, and vessel trip reports (NEFSC 1998, Link et al. 2002). By aggregating these data across the full range of targeted species in the NES LME, we contend that total landings is a measure of fishing pressure that is reasonably robust against variation in resource potential. These data cover the entire NES LME, span the years 1964 to 2010, and cover the full range of targeted species in the NES LME.

\section{Common environmental trends}

Many environmental pressures influence the structure of the NES LME. While a mechanistic understanding of how each pressure influences ecosystem structure is warranted and has been discussed elsewhere (Link et al. 2002, Methratta \& Link 2006, Shackell et al. 2012), our goal here was to identify how ecological indicators respond to the combined influence of fishing and environmental pressure. We used dynamic factor analysis (DynFA) to concentrate the variance from a broad range of important environmental pressure variables into a smaller number of interpretable patterns. Similar in concept to PCA, DynFA restricts axes by the temporal structure of the data and is commonly used to characterize ecological and environmental time series (Zuur et al. 2003, Friedland \& Hare 2007). Unlike PCA, however, DynFA trends are not ranked in order of importance. DynFA models time series as linear combinations of common trends, a level parameter, and noise, with models formulated as:

$$
y_{i, t}=z_{i, 1} \alpha_{1, t}+z_{i, 2} \alpha_{2, t}+\ldots+z_{i, m} \alpha_{m, t}+\mu+e_{i, t}
$$



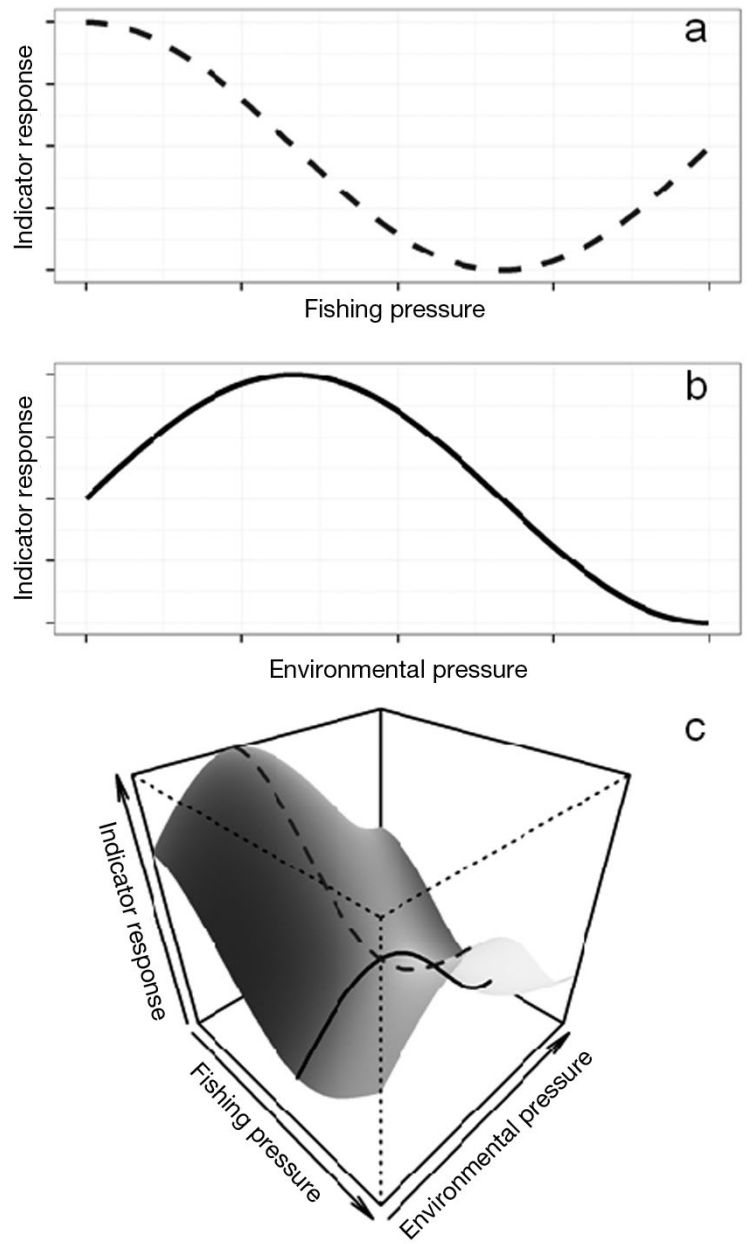

C

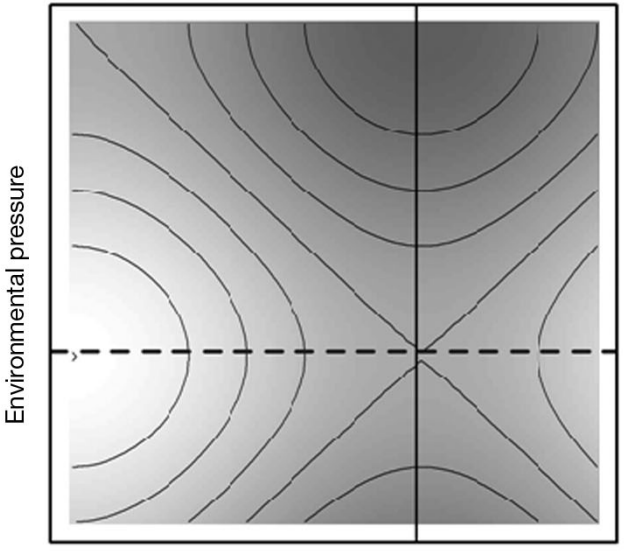

Fishing pressure
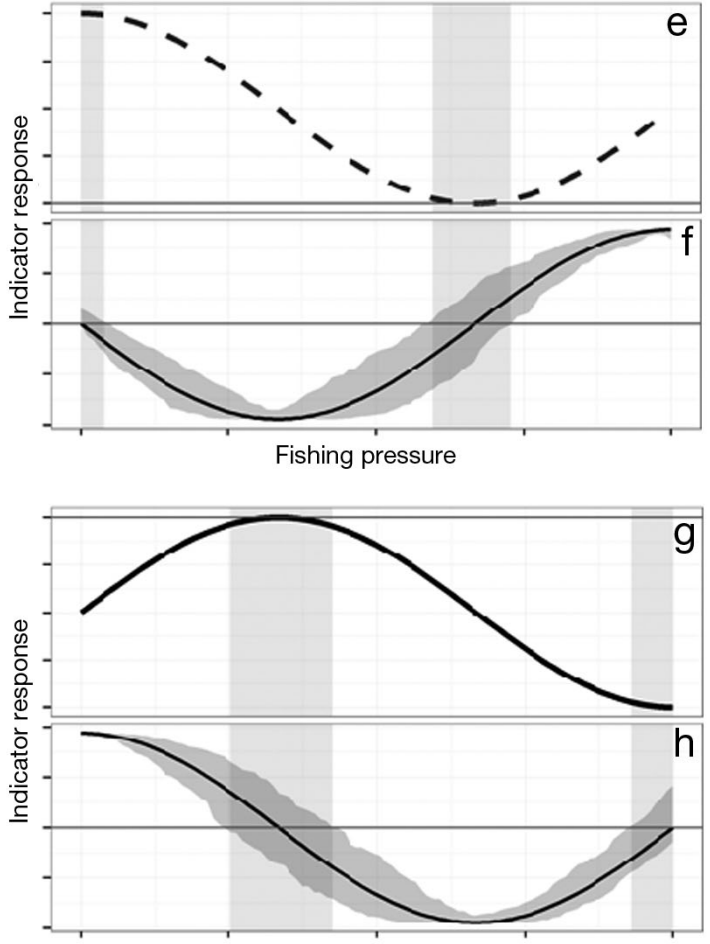

Environmental pressure

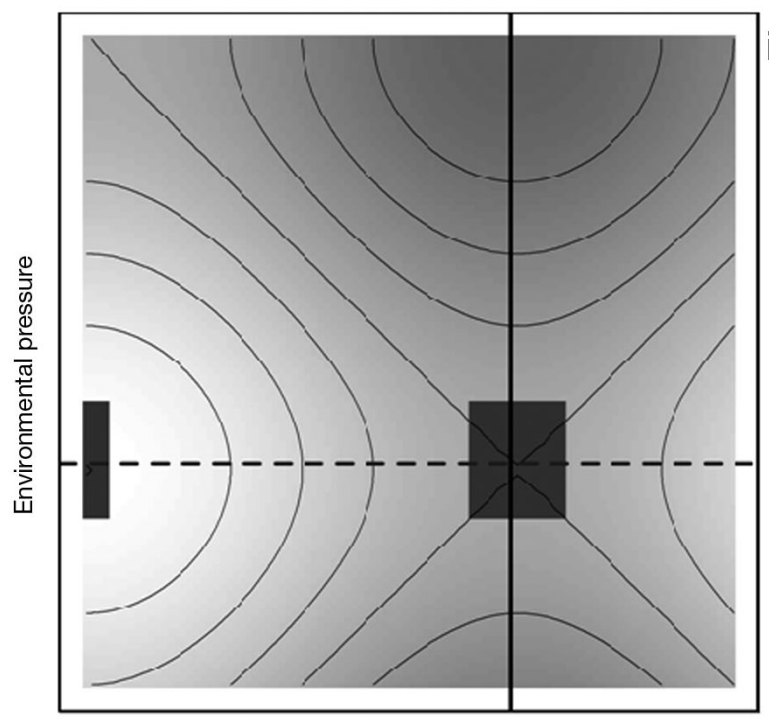

Fishing pressure

Fig. 1. Hypothetical relationship between an indicator, (a) fishing (dashed line), and (b) environmental (solid line) pressures can be viewed as 2 bivariate responses, or as a single surface described as a (c) 3-dimensional perspective plot or (d) a topographic plot, which both contain the relationships described as the dashed and solid lines in (a) and (b). Two-covariate thresholds are present when the first derivative (i.e. slope) of the relationships between indicator response and both (e) fishing and (g) environmental pressures are 0 . The $95 \%$ confidence interval of the first derivative of (f) fishing and (h) environmental pressures (dark gray shading around line) are used to identify regions where the slope is not significantly different from 0 (light gray vertical boxes). When the (i) relationship between the indicator and both fishing and environmental pressures crosses 0 , a dark polygon denotes a 2-covariate threshold. The second partial derivative test of this region can further describe it as local minima, maxima, or as a saddle point 
where $y_{t}$ is the value of the $i^{\text {th }}$ environmental time series at time $t, z_{i, m}$ is the factor loading for the $i^{\text {th }}$ time series and the $m^{\text {th }}$ common trend, $\alpha_{m, t}$ is the $m^{\text {th }}$ common trend at time $t, \mu$ is a constant level parameter, and $e_{i, t}$ is noise. Here, we specified the noise component $e_{i, t}$ as normally distributed with mean 0 and covariance matrix R (Zuur et al. 2003).

We standardized each environmental time series by subtracting the mean and scaling by the standard deviation. Next, we evaluated DynFA models of the environment with the number of common trends varying from 1 to 6 . We considered 2 structures for the error covariance matrix R: (1) diagonal and equal and (2) diagonal and unequal, both of which imply no covariance between trends. Diagonal and equal covariance matrices consider the same process variance across all time series, whereas diagonal and unequal covariance matrices consider unique variance values for each time series. DynFA was implemented with the multivariate autoregressive statespace (MARSS) package for R (modeling version 3.4; Holmes et al. 2013). Model selection for DynFA models with differing error covariance structures and the number of common trends was based on the lowest value of Akaike's information criterion corrected for small sample sizes (AICc; Hurvich \& Tsai 1989). The estimated common trends from the models selected by AICc were then used as representative of the composite environment pressure in subsequent analysis.

\section{Generalized additive model (GAM) analysis}

GAMs were used to create surfaces of ecological indicator responses to fishing and environmental pressures. We used finite differences to calculate partial derivatives of the surface to identify critical points and thresholds in indicator response to multiple pressures (Fig. 1). We fitted separate GAMs for each combination of ecological indicator and DynFA trend, along with fishing pressure (see 'Results: Critical points in 2-covariate GAMs', $\mathrm{n}=24$ models). Including DynFA trends in the GAM allowed us to account for multiple environmental variables in a single model. We fitted GAMs with the formula:

$$
I_{j}=\mu_{j}+s_{j}^{F}\left(F_{j}\right)+s_{j}^{E}\left(a_{j, m}\right)+\varepsilon_{j}
$$

where $I$ is the $j^{\text {th }}$ observation for the indicator, $F$ is fishing pressure, $a$ is the $m^{\text {th }}$ DynFA environmental trend, $s^{F}()$ and $s^{E}()$ are smoothing functions, and $\varepsilon$ is residual error. We reduced the likelihood of overfitting models by estimating the smoothing parameters with a generalized cross validation $\left(\mathrm{GCV}_{i}\right.$ Wood
2004) criterion as implemented in the $\mathrm{R}$ package 'mgcv' (Wood 2004). We included an additional ridge penalty enabling the smoothing term to be minimized to 0 through an eigenvalue optimization process (Wood 2003), which effectively allowed the model to eliminate smoothing terms into linear components. We also used typical model diagnostic procedures to check for evidence of autocorrelation and other violations of regression assumptions. After fitting each indicator to Eq. (2), we selected the most suitable model for each combination of predictors using the smallest AICc value.

GAMs are very flexible, and to ensure that thresholds are identified on suitable models, we further eliminated models based on the following criteria for both fishing and environmental pressure variables: (1) if the p-value of smoothing terms was greater than 0.05 , (2) if the estimated degrees of freedom (EDF) were close to their lower limit (i.e. models with EDF $\leq 1$ are effectively linear), and (3) if the GCV score for the model decreased once the smoothing term was removed from the model (Wood \& Augustin 2002). These criteria ensured that smoothed models were not selected when outperformed by linear terms and significant smoothers were present for both fishing and environmental pressure variables.

We measured uncertainty surrounding each GAM by using a maximum entropy bootstrap (MEboot) regimen as implemented in the R package 'meboot' version 1.1 (Vinod \& López-de-Lacalle 2009). MEboot differs from naïve bootstrap because it does not randomly sample with replacement all available data; rather, MEboot preserves the structure and properties of nonstationary and heteroscedastic data. Since our raw data were collected as time series, maintaining the innate data structure ensured models were fit to representative samples. Bootstrap replicates $(\mathrm{br}=i \ldots$ 1000) for ecological indicators and pressure variables were selected from the raw data, and each bootstrapped dataset was fit using a GAM as above. These GAM results were then evaluated for threshold criteria.

\section{Analysis of derivatives}

The shape of the relationship between an indicator and 2 pressure variables was captured as a surface composed of a function $f$. Here, we specified this surface $f$ as a GAM smoother, i.e. $s^{F}()$ and $s^{E}()$ for additive models. For a point $(a, b)$ on this surface, the slope was defined by 2 partial derivatives for each direction; the change in $x$ in the $x$ direction and the change in $x$ in the $y$ direction and vice versa (i.e. $f_{X}(x)$ 
and $f_{X}(y) ; f_{Y}(y)$ and $\left.f_{Y}(x)\right)$. If these partial derivatives passed beyond 0 , they indicated regions in each direction $x$ and $y$ where an indicator had a negative $\left(f_{X}(x)<0 ; f_{X}(y)<0\right)$ or positive $\left(f_{X}(x)>0 ; f_{X}(y)>0\right)$ slope in response to the pressure variables. Further, higher-order partial derivatives were also calculated, where $f_{X X}(x)$ was the rate of change in $x$ in the $x$ direction and $f_{X Y}(x)$ was the rate of change in $y$ in the $x$ direction. Critical points for the function $f$ were found when partial derivatives in the $x$ and $y$ direction both crossed 0 (i.e. $f_{X}(a, b)=f_{Y}(a, b)=0$ ). The second partial derivative test was used to classify a critical point as local maximum, minimum, or as a saddle point (see 'Partial Derivatives' in Strang 1991). For the determinant $M(x, y)=\operatorname{det}(H(x, y))=f_{X X}(x, y) f_{Y Y}(x, y)-\left(f_{X Y}(x)\right)^{2}$ if $f_{X}(a, b)=f_{Y}(a, b)=0$, it was a critical point of $f$ and the second partial derivative test specifies that:

(1) if $M(a, b)>0$ and $f_{x x}(a, b)>0$, then $(a, b)$ was a local minimum of $f$

(2) if $M(a, b)>0$ and $f_{X X}(a, b)<0$, then $(a, b)$ was a local maximum of $f$

(3) if $M(a, b)<0$, then $(a, b)$ was a saddle point of $f$

(4) if $M(a, b)=0$, then the second derivative test was inconclusive, and the point $(a, b)$ could be a minimum, maximum, or saddle point.

We used the principles above to identify critical points on the surface of the GAM smoother. We used the fitted GAM to predict a surface according to the original data and estimated the first- and secondorder partial derivates of this surface using finite differences (for a pressure-response example of these methods, see Large et al. 2013). To measure uncertainty surrounding these derivatives, we used the fitted GAM to predict surfaces for all bootstrap replicates and estimated all first- and second-order partial derivatives for each bootstrap replicated surface. Derivatives were sorted into ascending order, and the values of the $2.5 \%$ and $97.5 \%$ quantiles were considered the $95 \%$ CI for the first- and second-order partial derivatives of the GAM smoother. We identified critical points of the GAM smoother when we had $95 \%$ certainty that all partial derivatives contain 0 . When we identified a critical point, we used the second derivative test to qualify critical points as local extrema. Local maxima and minima represent a concurrent positive or negative influence by both pressure variables on an ecological indicator, whereas saddle points represent indicators that simultaneously changed in opposing directions in response to each pressure variable. These local extrema define thresholds in nonlinear responses between ecological indicators and pressures. In an EBFM context, these critical points represent potential ecological thresholds, and can clarify potential relationships between multiple variables. All analyses were conducted using $\mathrm{R}$ version 3.01 (R Development Core Team 2010).

\section{RESULTS}

\section{Common environmental trends}

The most suitable model of the dynamic factor models that we tested included 3 trends and a diagonal and unequal error covariance matrix (Table 2). The DynFA model provided only marginal improvement as a data reduction technique, as each trend represents variables that are positively and negatively correlated with it. However, the model did account for colinearity among environmental variables, which further justified the use of DynFA in subsequent analyses. The most parsimonious DynFA model fit the variability of environmental pressure time series reasonably well, as represented by the error covariance matrix, $\mathbf{R}$ (Table 3, Fig. 2). Here, low values of $\mathbf{R}$ indicate good model fit. The DynFA model fit AMO and SST reasonably well, and less than 20 and $35 \%$ of variance was left unexplained for each variable. GSNW, both NAO indices, stratification, and wind stress, however, were not well fit by the model, and $>50 \%$ of the variance of these variables was not explained by the model. DynFA trends are unitless; however, they were scaled and centered rel-

Table 2. Dynamic factor analysis (DynFA) model selection process. The trend at the top of the list was selected for further analyses. AICc: Akaike's information criterion corrected for small sample size

\begin{tabular}{|lccccc|}
\hline R matrix & Trends & $\begin{array}{c}\text { Log } \\
\text { likelihood }\end{array}$ & $\Delta$ AICC & $\begin{array}{c}\text { AICc } \\
\text { weight }\end{array}$ & $\begin{array}{c}\text { Cumulative } \\
\text { AICc weight }\end{array}$ \\
\hline Diagonal and unequal & $\mathbf{3}$ & -380.28 & 0.00 & 0.77 & 0.77 \\
Diagonal and equal & 3 & -388.82 & 3.17 & 0.16 & 0.93 \\
Diagonal and unequal & 2 & -388.52 & 4.84 & 0.07 & 1.00 \\
Diagonal and equal & 2 & -398.84 & 12.02 & 0.00 & 1.00 \\
Diagonal and equal & 4 & -388.82 & 12.39 & 0.00 & 1.00 \\
Diagonal and unequal & 4 & -382.66 & 14.37 & 0.00 & 1.00 \\
Diagonal and equal & 5 & -388.82 & 19.47 & 0.00 & 1.00 \\
Diagonal and unequal & 5 & -383.36 & 23.16 & 0.00 & 1.00 \\
Diagonal and equal & 6 & -388.82 & 24.27 & 0.00 & 1.00 \\
Diagonal and unequal & 6 & -383.36 & 28.18 & 0.00 & 1.00 \\
Diagonal and unequal & 1 & -412.62 & 39.59 & 0.00 & 1.00 \\
Diagonal and equal & 1 & -421.70 & 44.82 & 0.00 & 1.00 \\
\hline
\end{tabular}


Table 3. Values of $\mathrm{R}$ indicate the portion of variance in the environmental pressure time series that is unexplained by the dynamic factor analysis (DynFA). Low values indicate a good model fit. AMO: Atlantic multidecadal oscillation, NAO: North Atlantic oscillation

\begin{tabular}{|lc|}
\hline Environmental pressure & $\mathrm{R}$ \\
\hline AMO & 0.16 \\
Gulf Stream north wall & 0.49 \\
NAO (annual) & 0.64 \\
NAO (winter) & 0.56 \\
Sea surface temperature & 0.33 \\
Stratification & 0.70 \\
Wind stress & 0.54 \\
\hline
\end{tabular}

ative to the standard deviation and mean from environmental time series. Therefore, a DynFA trend's mean was equal to 0 and provided a reference point for interpretation. Interpreting DynFA trends is similar in concept to that of PCA, where DynFA trends are comparable to PCA axes on a biplot that act to concentrate the variance of environmental pressures. DynFA factor loadings are comparable to component vectors (i.e. arrows), where the relative value of factor loadings describes the association between environmental pressure time series and a particular trend, and a cut-off value of 0.2 delimits a strong association between environmental pressures and a DynFA
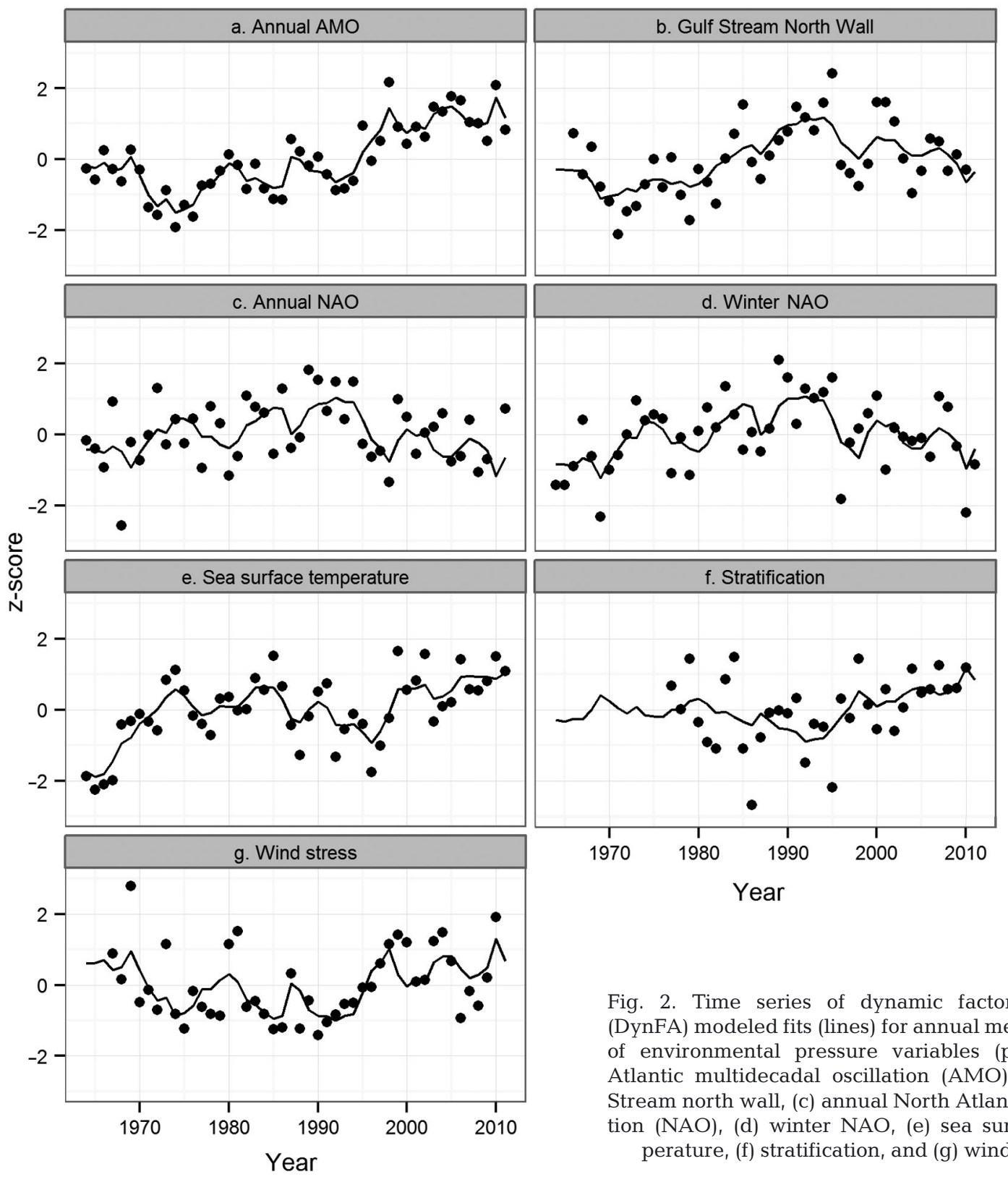

Fig. 2. Time series of dynamic factor analysis (DynFA) modeled fits (lines) for annual mean values of environmental pressure variables (points) (a) Atlantic multidecadal oscillation (AMO), (b) Gulf Stream north wall, (c) annual North Atlantic oscillation (NAO), (d) winter NAO, (e) sea surface temperature, (f) stratification, and (g) wind stress 
trend (Zuur et al. 2003). The first common trend rapidly declined during the late 1960s and gradually increased before leveling off at a high value in the early 2000s (Fig. 3a). AMO and wind stress had strong positive loadings on DynFA Trend 1, and both annual and winter NAO indices had strong negative factor loadings on this trend (Fig. 3b). After an initial decrease in the late $1960 \mathrm{~s}$, the second common trend increased between the early 1970s and 1990s and sub-
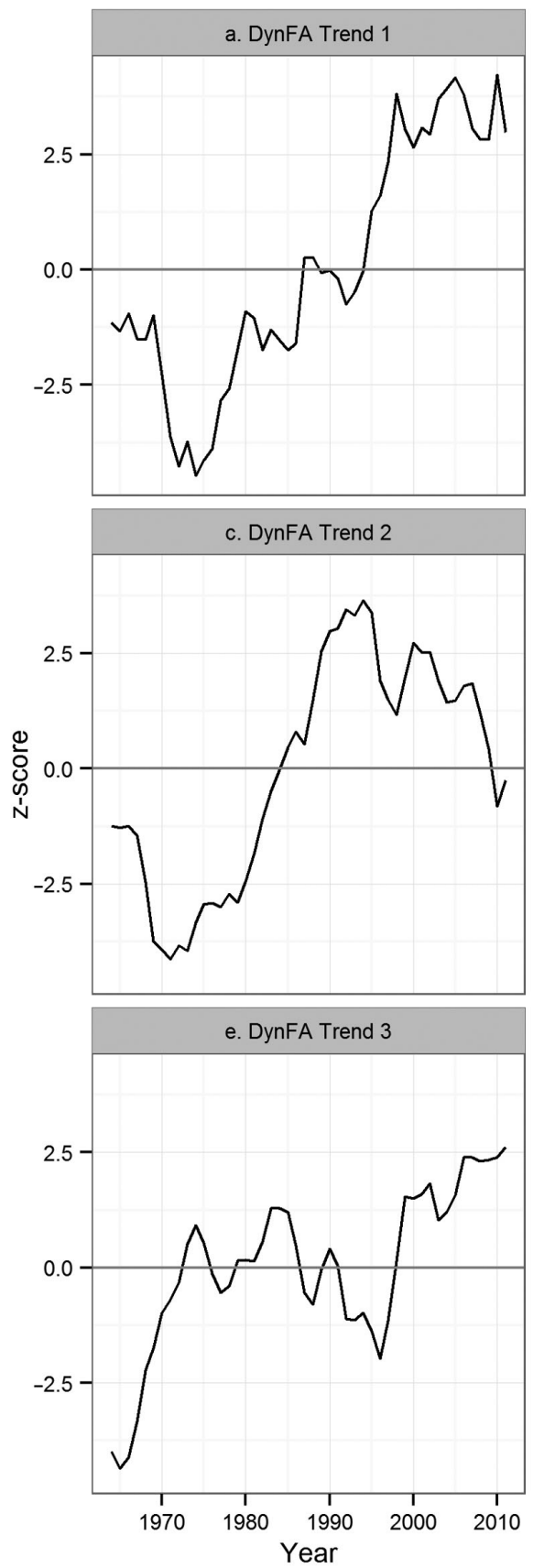

sequently decreased in the remaining decades (Fig. 3c). GSNW and both annual and winter NAO indices had strong positive factor loadings on DynFA Trend 2, and wind stress had strong negative factor loadings on this trend (Fig. 3d). The third common trend rapidly increased in the first decade of the time series, fluctuated about 0 , and continued to increase from the late 1990s until 2010 (Fig. 3e). SST had a strong positive factor loading on DynFA Trend 3 (Fig. 3f).
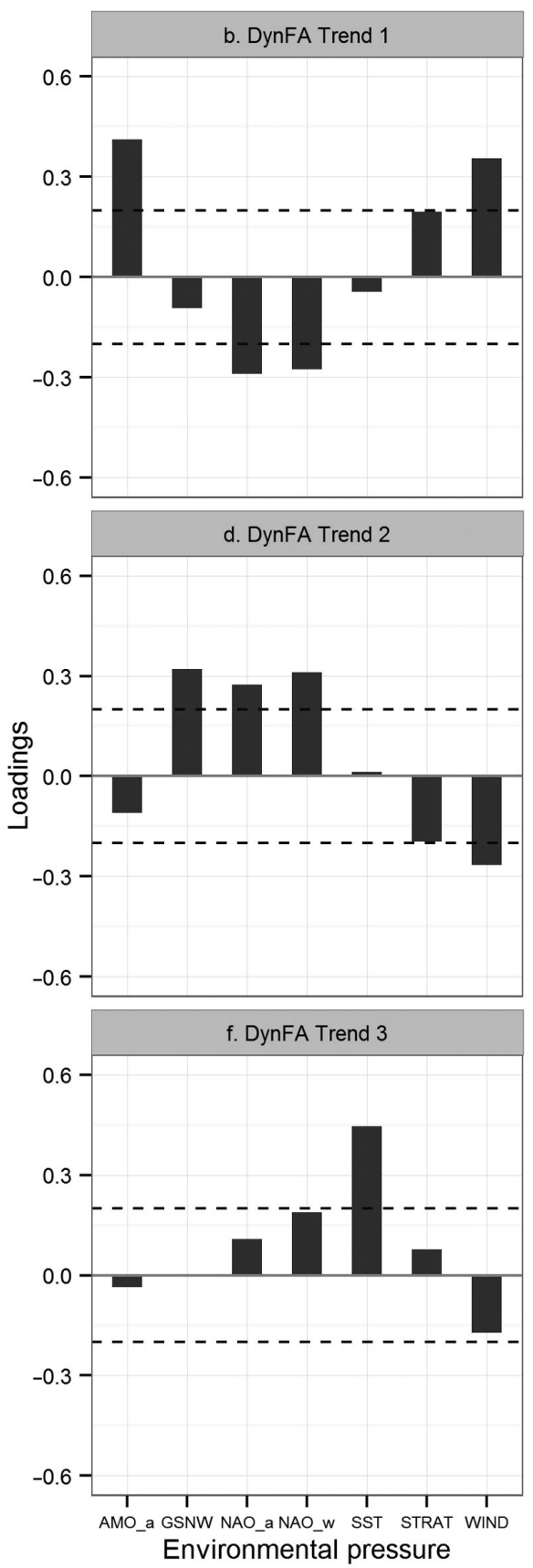

Fig. 3. $(\mathrm{a}, \mathrm{c}, \mathrm{e})$ Trends and $(\mathrm{b}, \mathrm{d}, \mathrm{f})$ factor loadings from the best dynamic factor analysis (DynFA) model. Loadings $>0.2$ and $<-0.2$ are considered important in the DynFA model, and these cut-off values are shown as dashed lines 


\section{Critical points in 2-covariate GAMs}

Of the 24 possible 2-covariate GAMs among ecological indicators, common DynFA trends, and fishing pressure, 22 included at least 1 significant $(\mathrm{p}<$ 0.05 ) term. Of these 22 significant models, 11 were reduced to linear models because the EDF $\leq 1.0$ or the GCV decreased when the smoothing term was removed. Three models contained only a single significant smoothing term, and the remaining 8 models included smoothing functions for both explanatory variables as smoothing functions (Table 4). Deviance explained by models that included smoothing functions for both covariates was greater than $50 \%$; however, models that did not include smoothing functions explained less than $50 \%$ of the deviance. The impetus of this study was to identify 2-covariate thresholds, so we focused on models that included significant nonlinear components for both explanatory variables. Finally, the entire range of pressure values was used to create the surface predicted from GAM smoothing functions. Since we were using this surface to model past realized combinations of pressure-environment-state space, we limited our interpretation of trends and thresholds to a minimum convex hull with a $10 \%$ buffer surrounding the raw data to prevent interpreting results beyond the spread of the raw data.

DynFA Trend 1 (DynFA 1 hereafter) was positively correlated with $\mathrm{AMO}$ and wind stress, and negatively correlated with both NAO indices. DynFA 1 and fishing pressure were significant pressure variables for 3 of the 8 ecological indicators: ctenophore abundance, length, and species richness (Table 4). Ctenophore abundance had a dome-shaped response to both DynFA 1 and fishing pressure. Saddle points were present when fishing pressure was approximately 400000 t and DynFA 1 was slightly higher than average ( 0.75; Fig. 4a). The intersection of these saddle points was also identified as a local maximum where ctenophore abundance was greatest. Length increased in response to both pressure variables, and saddle points (i.e. regions that increase in one direction and decrease in the other direction) were present

Table 4. Generalized additive model (GAM) results for each ecological indicator response to each dynamic factor analysis (DynFA) trend and fishing pressure. Bold $p$-values indicate significant $(p<0.05) 2$-covariate nonlinear models that were used in sub-sequent critical point analyses. s: smoothing function; NA: parameter not used in the best model

\begin{tabular}{|c|c|c|c|c|c|}
\hline \multirow[t]{2}{*}{ Ecological indicator } & \multirow{2}{*}{$\begin{array}{l}\text { Environmental } \\
\text { pressure }\end{array}$} & \multirow[t]{2}{*}{ Model } & \multicolumn{2}{|c|}{ p-value -} & \multirow{2}{*}{$\begin{array}{l}\text { Deviance } \\
\text { explained }\end{array}$} \\
\hline & & & Landings & Environment & \\
\hline \multirow[t]{3}{*}{ Longhorn sculpin biomass } & DynFA Trend 1 & $\mathrm{y} \approx$ Landings & 0.001 & NA & 0.45 \\
\hline & DynFA Trend 2 & $y \approx$ Landings & 0.001 & NA & 0.45 \\
\hline & DynFA Trend 3 & $y \approx$ Landings + Environment & 0.001 & 0.013 & 0.52 \\
\hline \multirow[t]{3}{*}{ Biomass } & DynFA Trend 1 & $y \approx$ Environment & NA & 0.001 & 0.47 \\
\hline & DynFA Trend 2 & $y \approx$ Landings + Environment & 0.090 & 0.102 & 0.34 \\
\hline & DynFA Trend 3 & $y \approx \mathrm{s}($ Landings $)+\mathrm{s}($ Environment $)$ & 0.003 & 0.001 & 0.68 \\
\hline \multirow[t]{3}{*}{ Ctenophore abundance } & DynFA Trend 1 & $y \approx \mathrm{s}($ Landings $)+\mathrm{s}($ Environment $)$ & 0.006 & 0.002 & 0.57 \\
\hline & DynFA Trend 2 & $y \approx \mathrm{s}($ Landings $)+$ Environment & 0.001 & 0.001 & 0.65 \\
\hline & DynFA Trend 3 & $y \approx$ Landings + Environment & 0.074 & 0.001 & 0.44 \\
\hline \multirow[t]{3}{*}{ Length } & DynFA Trend 1 & $y \approx \mathrm{s}($ Landings $)+\mathrm{s}($ Environment $)$ & 0.001 & 0.001 & 0.52 \\
\hline & DynFA Trend 2 & $y \approx \mathrm{s}($ Landings $)+\mathrm{s}($ Environment $)$ & 0.001 & 0.002 & 0.53 \\
\hline & DynFA Trend 3 & $y \approx \mathrm{s}($ Landings $)+\mathrm{s}($ Environment $)$ & 0.019 & 0.001 & 0.60 \\
\hline \multirow[t]{3}{*}{ Pelagic to demersal ratio } & DynFA Trend 1 & $y \approx$ Landings $+\mathbf{s}($ Environment $)$ & 0.001 & 0.001 & 0.88 \\
\hline & DynFA Trend 2 & $y \approx \mathrm{s}($ Landings $)+\mathrm{s}($ Environment $)$ & 0.001 & 0.001 & 0.92 \\
\hline & DynFA Trend 3 & $y \approx \mathrm{s}($ Landings $)+\mathrm{s}($ Environment $)$ & 0.001 & 0.001 & 0.67 \\
\hline \multirow[t]{3}{*}{ Planktivores and benthivores } & DynFA Trend 1 & $y \approx$ Environment & NA & 0.001 & 0.42 \\
\hline & DynFA Trend 2 & $y \approx$ Environment & NA & 0.001 & 0.41 \\
\hline & DynFA Trend 3 & $y \approx$ Landings + Environment & 0.001 & 0.129 & 0.26 \\
\hline \multirow[t]{3}{*}{ Species richness } & DynFA Trend 1 & $y \approx \mathrm{s}($ Landings $)+\mathrm{s}($ Environment $)$ & 0.001 & 0.001 & 0.78 \\
\hline & DynFA Trend 2 & $y \approx \mathrm{s}($ Landings $)$ & 0.001 & NA & 0.39 \\
\hline & DynFA Trend 3 & $y \approx$ Landings + Environment & 0.003 & 0.001 & 0.70 \\
\hline \multirow[t]{3}{*}{ Trophic level } & DynFA Trend 1 & $y \approx \mathrm{s}($ Environment $)$ & 0.066 & NA & 0.07 \\
\hline & DynFA Trend 2 & $y \approx$ Environment & NA & 0.027 & 0.10 \\
\hline & DynFA Trend 3 & $y \approx$ Landings + Environment & 0.020 & 0.140 & 0.12 \\
\hline
\end{tabular}


when DynFA 1 values were slightly below average (approx. -1.0; Fig. 4b). Species richness decreased in response to fishing pressure and when DynFA 1 was near 0 ; however, this relationship did not have any significant critical points (Fig. 4c).

DynFA Trend 2 (hereafter DynFA 2) represented positive loadings for both NAO indices and GSNW, and negative loadings for AMO and wind stress. DynFA 2 and fishing pressure were significant pressure variables for 2 of the 8 ecological indicators: length and pelagic to demersal ratio (Table 4). Length increased with fishing pressure and was greatest when DynFA 2 was slightly below the mean. Saddle points were present when DynFA 2 was approximately 0, and length was much lower when DynFA 2 was above or below 0 (Fig. 5a). Pelagic to demersal ratio increased in response to DynFA 2 and decreased in response to fishing pressure. Saddle points were present when fishing pressure was approximately $400000 \mathrm{t}$ (Fig. 5b) and DynFA 2 was negative. Below 400000 t, the relationship between pelagic to demersal ratio and fishing pressure was positive, and the relationship turned negative above $400000 \mathrm{t}$.

DynFA Trend 3 (hereafter DynFA 3) had strong positive loadings for SST. DynFA 3 and fishing pressure were significant pressure variables for 3 of the 8 ecological indicators: biomass, length, and pelagic to demersal ratio. Biomass was variable in response to DynFA 3 and decreased in response to fishing pressure. A local minimum was present when fishing pressure was $800000 \mathrm{t}$ and DynFA 3 was slightly below the mean (Fig. 6a). Length decreased in response to DynFA 3 and marginally increased in response to fishing pressure; however, this relationship did not have any significant critical points (Fig. 6b). Pelagic to demersal ratio decreased in response to fishing pressure and was greatest corresponding to saddle points when DynFA 3 was slightly below the mean (approx. -1 ; Fig. 6c).

Fig. 4. Topographic surfaces represent the pressure-environment-state fit of 2 covariate generalized additive models. A minimum convex hull with a $10 \%$ buffer surrounding the raw data (dashed polygon) and rug plots along the top and right margins provide an estimate of data distribution across each model fit. Shaded polygons are significant critical points that fall within $95 \%$ CI of 0 for partial derivatives in both directions, indicating no significant difference from 0 . The second partial derivative test (described in the 'Materials and methods: Analysis of derivatives') was used to define each polygon as local maximum (dark gray), saddle points (gray), or local minimum (light gray). (a) Ctenophora abundance, (b) mean length, and (c) species richness response to fishing pressure and dynamic factor analysis (DynFA) 1
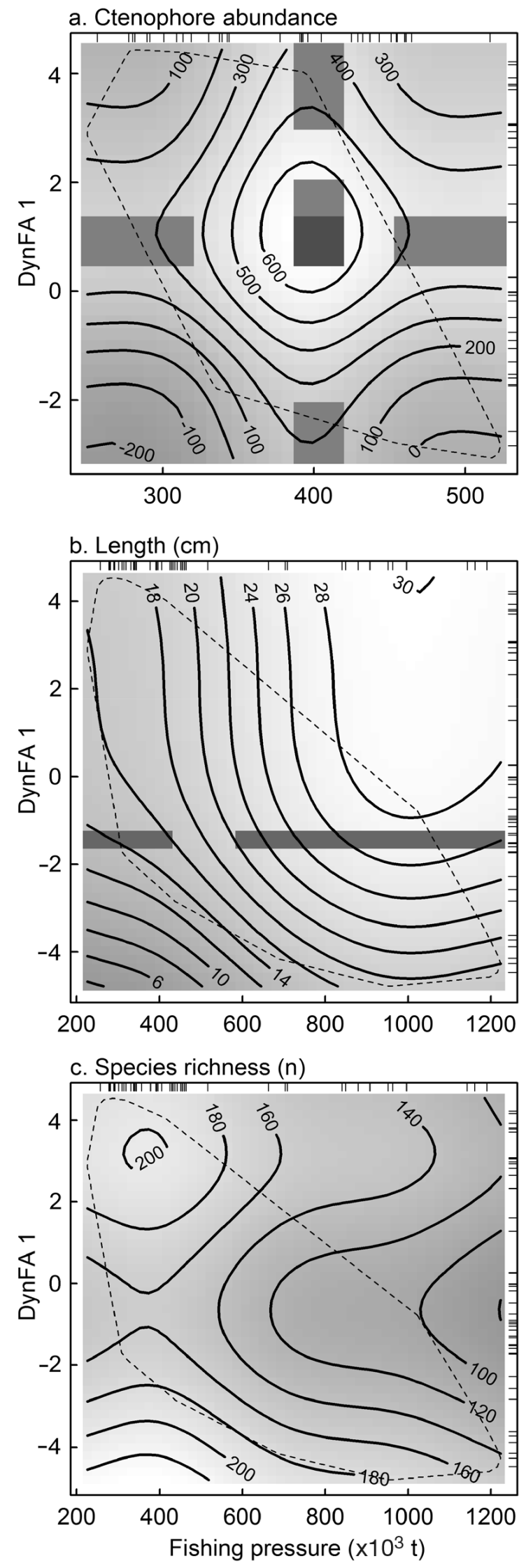


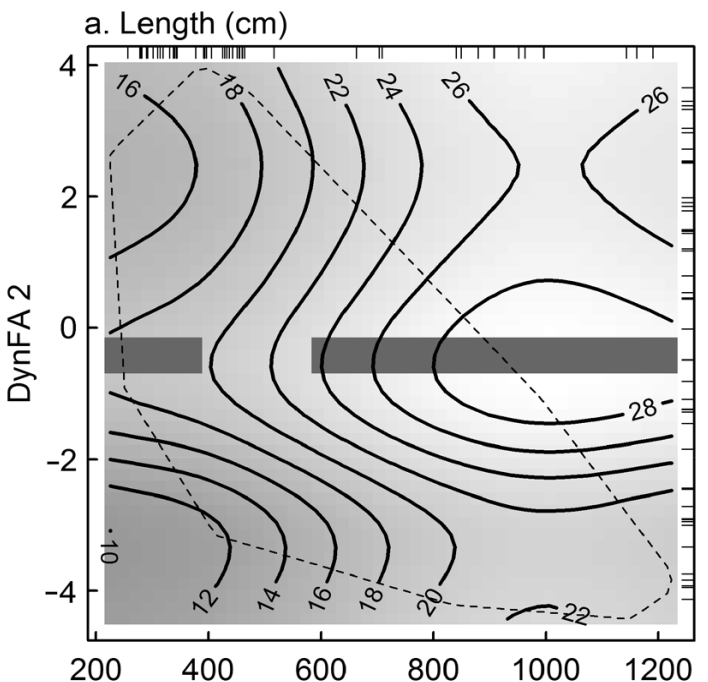

b. Pelagic to demersal ratio (index)

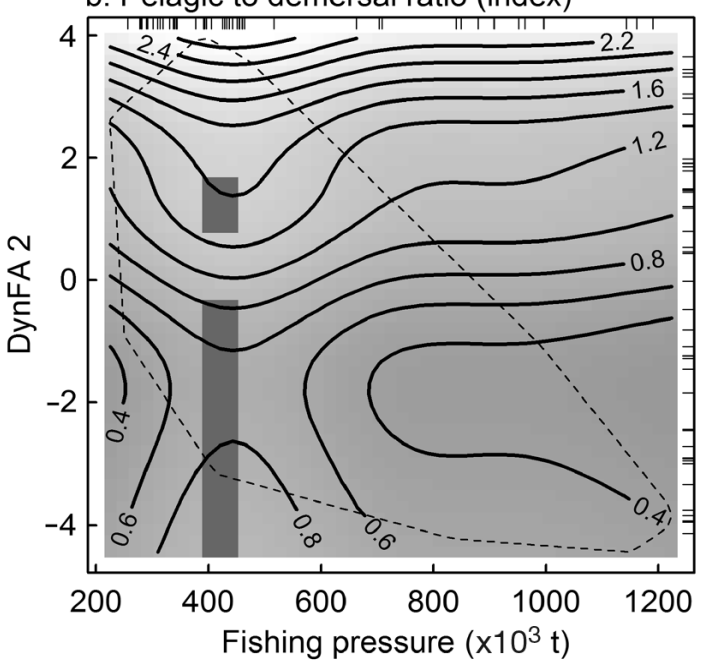

Fig. 5. (a) Mean length and (b) pelagic to demersal ratio response to fishing pressure and dynamic factor analysis (DynFA) 2. Details as in Fig. 4

\section{DISCUSSION}

In this study, we applied the concept of pressureresponse thresholds (Large et al. 2013) to 2-covariate relationships by translating ecological indicator response into a surface dependent on both fishing and environmental pressures. Our approach used concepts borrowed from calculus and bolstered with a time-series appropriate bootstrap regimen (Vinod \& López-de-Lacalle 2009) to identify critical points in ecosystem response to multiple pressures. Critical points were identified when the rate of change of an indicator with respect to both pressure variables crossed 0, which represented levels of pressure where ecosystems had an abrupt nonlinear change in direc-
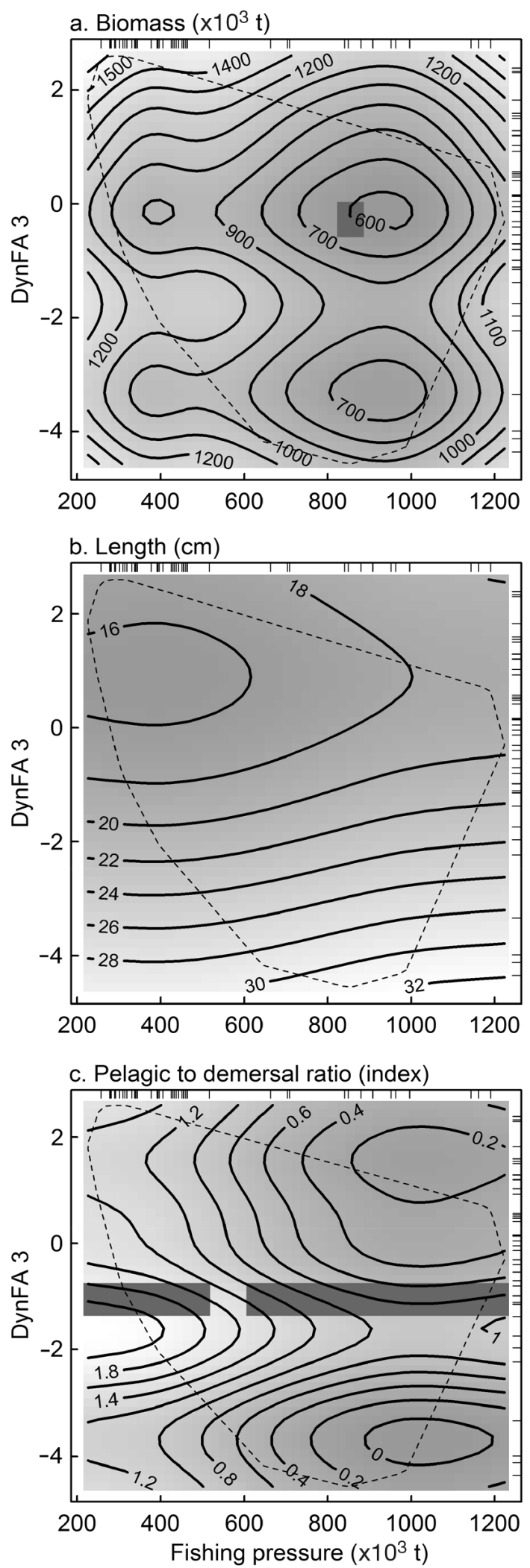

Fig. 6. (a) Biomass, (b) mean length, and (c) pelagic to demersal ratio response to fishing pressure and dynamic factor analysis (DynFA) 3. Details as in Fig. 4 
tion, and as such may represent ecological thresholds. These ecological thresholds can be used to examine past realized combinations in the pressureenvironment-state space to further understand how anthropogenic pressure may influence ecosystem structure and function while concurrently accounting for environmental variation.

\section{Strengths and weaknesses of the method}

Generalized additive modeling is a robust statistical framework commonly used to identify nonlinear relationships (Hastie \& Tibshirani 1990). One criticism of GAMs is the propensity to over-fit the model to the data. Parameterizing models to be selective against overly curvaceous models, yet sensitive to appropriate nonlinear models can prove challenging. As such, reconciling trade-offs between model selectivity and sensitivity is important in defining decision criteria. We specified our models to prevent overfitting and to be conservative against nonlinear relationships by using penalized regression splines and a priori model selection criteria (Wood \& Augustin 2002, Wood 2003), and we identified significant 2-covariate nonlinear relationships in one-third of our models. With more lenient selection criteria, we may have identified more significant nonlinear 2-covariate pressure-response relationships; however, these relationships may not have been suitably robust. Since a suite of ecological indicators is necessary to capture ecosystem response to pressures (Rice \& Rochet 2005), we propose that strong signals from a few indicators may be more advantageous than weak signals from many indicators.

Ecosystems are inherently complex, and multivariate techniques are often used to characterize environmental processes into general patterns that describe ecosystem processes and facilitate comprehension and comparison (Shackell et al. 2012). We used DynFA to simplify the main environmental pressure variables for the NES LME into a selection of common trends that represent ecosystem responses and concentrate the variance such that each DynFA trend might conceptually represent a different dimension of this variance. By using DynFA common trends as explanatory variables, we also reduced the number of models necessary to characterize the relationships of interest and were not constrained by colinearity between environmental variables. For example, if we had fit GAMs for each combination of ecological indicator and fishing and environmental pressure, we would have had 64 unique 2-covariate models. The DynFA approach concentrated environmental variance into 3 common trends, and the number of models was reduced to 24 , decreasing the likelihood of false correlations. The ability to identify critical points between ecological indicators, fishing, and specific environmental pressures was diminished (although the latter could be inferred from factor weightings); however, DynFA provided a suitable balance between explanatory power and dimension reduction.

\section{Critical points and ecological thresholds}

Converting ecological indicators into suitable decision criteria is necessary to operationalize EBFM (Link 2005, Samhouri et al. 2010). In this study, we examined thresholds that represent the level of an indicator at which a small increase in a pressure variable results in an abrupt change in the direction of indicator response, which can be used to maximize ecosystem return on investment for a management decision (Groffman et al. 2006). Thresholds are advantageous from a management perspective because a small change in a pressure can result in a substantial improvement in system, or ecosystem, status (Samhouri et al. 2010). These approaches are nascent but growing in a wide range of ecological applications (Andersen et al. 2009, Clements et al. 2010, Fay et al. 2013, Large et al. 2013). In single-species fisheries management parlance, the concept of thresholds are captured in reference points such as $B_{m s y}$ or $F_{m s y}$, where crossing beyond a certain population attribute may result in decreased stock status or fisheries' yield (Hilborn \& Walters 1992). We identified critical points, or 2-covariate thresholds, in ecological indicators that represent system production (total biomass), size distribution (mean length), community structure (pelagic to demersal ratio), and ecosystem functioning (ctenophore abundance). Abrupt changes in the direction of these fundamental ecosystem features in response to multiple pressures highlight the importance of integrating multiple dimensions of information to better understand ecosystem level responses to complex relationships between multiple pressures. Yet not all critical points are the same. Saddle points were the most common type of critical point identified in our study and represent situations where the environment could have a positive influence on indicator status while fishing pressure has a negative influence. For example, the response of mean length to fishing and DynFA 2 contained saddle points when the value of DynFA 2, primarily 
representative of positive NAO indices and negative wind stress, was slightly less than 0 . Mean length increased with fishing pressure, but was greatest when the value of DynFA 2 was slightly below the mean. Counterintuitively, the ecological indicator was positively linked to fishing pressure, and the magnitude of the indicator value was negatively linked to the environmental pressure. This implies that environmental factors can mitigate or offset known effects from fishing pressures, and vice versa (Link et al. 2012). Ecosystems respond to opposing signals from a variety of pressures, and ecological indicators may be negatively influenced by fishing or the environment, while simultaneously being positively influenced by another pressure.

Critical points representing local extrema were also identified in our study. For example, ctenophore abundance was greatest when fishing pressure was approximately 400000 t and DynFA 1, representative of positive AMO and wind stress and negative NAO indices, was approximately 1.0. Ctenophore abundance rapidly decreased when both pressure values were above or below these critical points. Similarly, total survey biomass was lowest when fishing pressure was $800000 \mathrm{t}$ and DynFA 3, representative of positive SST loadings, was approximately 0 . Total survey biomass was much higher away from high pressure values. Therefore, ecosystem status might be influenced by additive or multiplicative signals from multiple pressures, and ecological indicator response may be much more (or less) than otherwise expected.

We used an additive approach to parameterize our models, and our findings describe the combined ecological indicator response to fishing and environmental pressures. Preliminary analyses investigated interactions between fishing and environmental pressures; however, these relationships did not fundamentally change the pressure-environment-state surface or associated critical points. Further, including interactions added an additional layer of complexity to an already highly dimensional analysis. Recent studies and reviews highlight the prevalence of non-additive (i.e. synergistic or antagonistic) interactions between multiple stressors in marine ecosystems (e.g. Crain et al. 2008). Modeling exercises for the NES LME, however, have found additive effects more prevalent (Nye et al. 2013). Identifying non-additive interactions between multiple pressures could be an important consideration for EBFM because cumulative effects could be much greater than expected and may require stricter management (Nye et al. 2013). We suggest that future studies exploring the prevalence and potential outcomes of non-additive interactions on ecological thresholds should include ensemble methods such as the gradient forest method (Large et al. unpubl.).

\section{Decision criteria}

Fisheries production and ecosystem status have been linked to multiple drivers including fishing, trophodynamics, and the environment (Gaichas et al. 2012, Link et al. 2012). In a management context, establishing limits for multiple pressures quickly becomes complex. Exploring the past realized pressure-environment-state surfaces can be helpful in identifying patterns where multiple pressures may have contributed to altered ecosystem states, and can also be used to inform future management choices. The NES LME has experienced substantial variation in fleet size, targeted species, and allowable catch limits since the middle of the $20^{\text {th }}$ century. During the early 1960s, distant water fleets rapidly overexploited multiple species including haddock, silver hake, herring, and mackerel, but important groundfish such as cod were not overexploited (Fogarty \& Murawski 1998). Fishing pressure was greatest during this time and our analyses identified the NES LME as a pelagic depleted system (i.e. low pelagic to demersal ratio) dominated by larger fish (i.e. longer mean length), which has been noted elsewhere (EcoAP 2009). Our critical point analysis identified a significant threshold at $\sim 400000$ t landings, suggesting that above this level of exploitation there was a change in the direction of ecosystem structure (i.e. pelagic to demersal ratio) and functioning (i.e. ctenophore abundance) in the NES LME. Furthermore, environmental pressures also influenced the NES LME ecosystem status. DynFA 3 had strong positive factor loadings from SST, and when temperatures were cooler than average, the NES LME was a pelagic-dominated system (i.e. high pelagic to demersal ratio), which has been shown in other studies (e.g. Rose 2005). When temperatures departed from this level, the NES LME rapidly changed in biomass and community composition. Therefore, we can use the past realized pressure-environment-state surfaces for the NES LME to help describe patterns in ecosystem response and identify thresholds that signify an abrupt change in ecosystem structure.

We evaluated ecological indicator response to multiple pressure variables and found that each ecological indicator response differed according to both fishing and the environmental pressure. Combining univariate ecological thresholds into synthetic, multi- 
variate decision criteria might better represent ecological status. Future studies should evaluate ecological thresholds as a suite of ecological indicators using ensemble or multivariate approaches, which will develop an understanding of ecosystem thresholds (cf. Link et al. 2002). Additionally, simulation modeling and model validation using a management strategy evaluation framework might be used to evaluate potential ecosystem responses to decision criteria derived from ecological thresholds (Fay et al. 2013 , 2014). Understanding how to combine multiple thresholds (e.g. ecological, socio-economic) to create ecosystem thresholds will facilitate decision criteria to support management action.

How would one use these thresholds to act in a management setting? For example, the pelagic to demersal ratio is a common ecological indicator used to describe energy transfer and food-web structure (de Leiva Moreno et al. 2000, Methratta \& Link 2006, Nye et al. 2013). If our management objective was to maintain an ecosystem with the pelagic to demersal ratio between 1.2 and 1.4, a region of the response surface known to correspond to desirable ecosystem conditions (Fogarty \& Murawski 1998), we could maintain fishing pressure at or below the $400000 \mathrm{t}$ threshold and still maintain our desired ecological indicator value. However, the value of the ecological indicator is also highly dependent upon environmental state. In response to DynFA Trend 2 (characterized largely by positive NAO and negative wind stress) and fishing pressure, the pelagic to demersal ratio between 1.2 and 1.4 only occurred when DynFA Trend 2 was greater than $\sim 1.0$. When DynFA Trend 2 was less than 1.0, the pelagic to demersal ratio was never within the observed range, thereby obviating our ability to achieve our management objective. We conclude that multiple pressures can be important and that the magnitude of indicator response and ecological thresholds are highly conditioned upon multiple pressure variables. Including both anthropogenic and environmental pressures is essential when setting these ecosystem-level decision criteria.

\section{Conclusions}

Natural environmental variability (Beaugrand et al. 2008) and human exploitation (Myers et al. 1997, Pauly et al. 1998, Link et al. 2012) both influence marine ecosystem structure and function. As scientists, managers, and policy makers move towards the implementation of ecosystem-based approaches to management, reference points for management action need to be developed. Our results indicate that ecosystem attributes may have either linear or abrupt and non-linear responses to both fishing and environmental pressures for the NES LME. Both linear and non-linear responses are important and useful to inform management decision. Linear relationships indicate that related ecosystem decisions fall strictly in the realm of policy, and science cannot clearly distinguish between states, whereas nonlinear relationships may contain distinct critical points where ecosystem status can be maximized (Samhouri et al. 2012). We suggest that the values of these critical points can be used to identify magnitudes of pressures that might result in abrupt ecosystem change. Further, these critical points can be included in simulation modeling exercises to more fully understand ecosystem dynamics and potential tradeoffs as we develop decision criteria to support ecosystem-based approaches to management.

The approach we present here has broad applications beyond fisheries management. Threshold analyses have been used to explore changes in ecological response time series to prioritize conservation efforts (Fewster et al. 2000) and to assess recovery in degraded ecosystems (Clements et al. 2010). Similarly, threshold analyses have also looked at changes in an attribute's response to a single pressure, such as coral reef health to fishing pressure (Bellwood et al. 2004) or ecosystem responses to lake eutrophication (Carpenter et al. 1999). However, each of these examples likely has multiple pressures acting on the system simultaneously, and exploring the surface of response over time or multiple pressure space could improve the ability to formulate meaningful decision criteria. The method we present here holds promise for informing decision criteria to multiple pressures because (1) it describes ecosystem patterns via robust ecological indicators, (2) it is flexible to implement since it is only reliant on a suitable GAM surface to identify patterns and critical points, and (3) it is extendible to multiple pressures with the application of DynFA.

The need to implement a more holistic management framework, such as EBM, is apparent because living resources and the ecosystems that they function within are affected by a range of perturbations including effects from anthropogenic sources and those associated with natural environmental variability. To facilitate the implementation of EBM, a practical method to address all potential stressors and cumulative impacts simultaneously on a variety of ecosystem attributes is to use ecological indicator thresholds to inform decision criteria for manage- 
ment action. As Andrewartha \& Birch (1954) noted so long ago, we often see the most striking ecosystem response when competing forces interact, and we note the potential for complex relationships (e.g. synergistic and antagonistic) between multiple pressure variables. As the application of ecological thresholds continues to develop, these relationships should be explored further. The approach we present here will provide yet another step towards facilitating the implementation of EBM by clarifying how multiple pressures influence ecosystem status, and how these responses can be applied to formulate decision criteria for management action.

Acknowledgements. This work was supported by a NOAA NMFS Fisheries and the Environment (FATE) grant. We thank all those who participated in the NEFSC bottom trawl survey and have maintained this database. We thank B. Wells, J. Samhouri, and 2 anonymous reviewers for their thoughtful comments on earlier versions of this work.

\section{LITERATURE CITED}

Allen CD, Savage M, Falk DA, Suckling KF and others (2002) Ecological restoration of Southwestern ponderosa pine ecosystems: a broad perspective. Ecol Appl 12: 1418-1433

Andersen T, Carstensen J, Hernández-García E, Duarte CM (2009) Ecological thresholds and regime shifts: approaches to identification. Trends Ecol Evol 24:49-57

Andrewartha HG, Birch LC (1954) The distribution and abundance of animals. University of Chicago Press, Chicago, IL

Azarovitz T (1981) A brief historical review of the Woods Hole Laboratory trawl survey time series. Publ Spec Can Sci Halieut Aquat 58:62-67

Beaugrand G, Edwards M, Brander K, Luczak C, Ibanez F (2008) Causes and projections of abrupt climate-driven ecosystem shifts in the North Atlantic. Ecol Lett 11: $1157-1168$

Bellwood DR, Hughes TP, Folke C, Nyström M (2004) Confronting the coral reef crisis. Nature 429:827-833

> Bianchi G, Gislason H, Graham K, Hill L and others (2000) Impact of fishing on size composition and diversity of demersal fish communities. ICES J Mar Sci 57:558-571

> Bundy A, Shannon LJ, Rochet MJ, Neira S, Shin YJ, Hill L, Aydin K (2010) The good(ish), the bad, and the ugly: a tripartite classification of ecosystem trends. ICES J Mar Sci 67:745-768

> Carpenter SR, Ludwig D, Brock WA (1999) Management of eutrophication for lakes subject to potentially irreversible change. Ecol Appl 9:751-771

> Christensen NL, Bartuska AM, Brown JH, Carpenter S and others (1996) The report of the Ecological Society of America committee on the scientific basis for ecosystem management. Ecol Appl 6:665-691

Clements WH, Vieira NKM, Sonderegger DL (2010) Use of ecological thresholds to assess recovery in lotic ecosystems. J N Am Benthol Soc 29:1017-1023

Crain CM, Kroeker K, Halpern BS (2008) Interactive and cumulative effects of multiple human stressors in marine systems. Ecol Lett 11:1304-1315

de Leiva Moreno J, Agostini V, Caddy J, Carocci F (2000) Is the pelagic-demersal ratio from fishery landings a useful proxy for nutrient availability? A preliminary data exploration for the semi-enclosed seas around Europe. ICES J Mar Sci 57:1091-1102

EcoAP (Ecosystem Assessment Program) (2009) Ecosystem status report for the Northeast U.S. Continental Shelf Large Marine Ecosystem. NEFSC Ref Doc 09-11, available at http://nefsc.noaa.gov/publications/crd/crd0911

EcoAP (2012) Ecosystem status report for the Northeast Shelf Large Marine Ecosystem - 2011. NEFSC Ref Doc 12-07, available at http://nefsc.noaa.gov/publications/ $\mathrm{crd} / \mathrm{crd} 1207$

Enfield DB, Mestas-Nunez AM, Trimble PJ (2001) The Atlantic multidecadal oscillation and its relation to rainfall and river flows in the continental U.S. Geophys Res Lett 28:2077-2080

Fay G, Large SI, Link JS, Gamble RJ (2013) Testing systemic fishing responses with ecosystem indicators. Ecol Model 265:45-55

> Fay G, Link JS, Large SI, Gamble RJ (2014) Management performance of ecological indicators in the Georges Bank finfish fishery. ICES J Mar Sci, doi:10.1093/icesjms/ fsu214

- Fewster RM, Buckland ST, Siriwardena GM, Baillie SR, Wilson JD (2000) Analysis of population trends for farmland birds using generalized additive models. Ecology 81: 1970-1984

Fogarty MJ, Murawski SA (1998) Large-scale disturbance and the structure of marine systems: fishery impacts on Georges Bank. Ecol Appl 8:S6-S22

Friedland KD, Hare JA (2007) Long-term trends and regime shifts in sea surface temperature on the continental shelf of the northeast United States. Cont Shelf Res 27: 2313-2328

> Gaichas SK, Bundy A, Miller TJ, Moksness E, Stergiou KI (2012) What drives marine fisheries production? Mar Ecol Prog Ser 459:159-163

- Groffman PM, Baron JS, Blett T, Gold AJ and others (2006) Ecological thresholds: the key to successful environmental management or an important concept with no practical application? Ecosystems 9:1-13

Hastie TJ, Tibshirani RJ (1990) Generalized additive models. Chapman \& Hall/CRC, Boca Raton, FL

Hilborn R, Walters C (1992) Quantitative fisheries stock assessment: choice, dynamics, and uncertainty. Chapman \& Hall, New York, NY

Holmes EE, Ward EJ, K. Wills K (2013) MARSS: multivariate autoregressive state-space modeling. $\mathrm{R}$ package version 3.4. Available at http://cran.r-project.org/web/packages/ MARSS/

Hsieh CH, Reiss CS, Hunter JR, Beddington JR, May RM, Sugihara G (2006) Fishing elevates variability in the abundance of exploited species. Nature 443:859-862

Hurrell JW (1995) Decadal trends in the North Atlantic Oscillation: regional temperatures and precipitation. Science 269:676-679

Hurvich CM, Tsai CL (1989) Regression and time series model selection in small samples. Biometrika 76:297-307

Jennings S (2005) Indicators to support an ecosystem approach to fisheries. Fish Fish 6:212-232

Lackey RT (1998) Seven pillars of ecosystem management. Landsc Urban Plan 40:21-30 
Large SI, Fay G, Friedland KD, Link JS (2013) Defining trends and thresholds in responses of ecological indicators to fishing and environmental pressures. ICES J Mar Sci 70:755-767

Larkin P (1996) Concepts and issues in marine ecosystem management. Rev Fish Biol Fish 6:139-164

Link JS (2002) What does ecosystem-based fisheries management mean? Fisheries 27:18-21

Link JS (2005) Translating ecosystem indicators into decision criteria. ICES J Mar Sci 62:569-576

Link JS, Brodziak JKT (eds) (2002) Report on the status of the Northeast U.S. continental shelf ecosystem. NEFSC Ref Doc 02-11, available at http://nefsc.noaa.gov/publications/crd/crd0211

Link JS, Ford MD (2006) Widespread and persistent increase of Ctenophora in the continental shelf ecosystem off NE USA. Mar Ecol Prog Ser 320:153-159

Link JS, Brodziak JKT, Edwards SF, Overholtz WJ and others (2002) Marine ecosystem assessment in a fisheries management context. Can J Fish Aquat Sci 59: $1429-1440$

> Link JS, Gaichas S, Miller TJ, Essington T and others (2012) Synthesizing lessons learned from comparing fisheries production in 13 northern hemisphere ecosystems: emergent fundamental features. Mar Ecol Prog Ser 459: 293-302

Methratta ET, Link JS (2006) Evaluation of quantitative indicators for marine fish communities. Ecol Indic 6:575-588

Murawski SA (2000) Definitions of overfishing from an ecosystem perspective. ICES J Mar Sci 57:649-658

Myers RA, Hutchings JA, Barrowman NJ (1997) Why do fish stocks collapse? The example of cod in Atlantic Canada. Ecol Appl 7:91-106

NEFC (Northeast Fisheries Center) (1988) An evaluation of the bottom trawl survey program of the Northeast Fisheries Science Center. NOAA Tech Memo NMFS-F/ NEC-52

NEFSC (Northeast Fisheries Science Center) (1998) Status of fishery resources off the Northeastern United States for 1998. NOAA Tech Memo NMFS-NE-115

- Nye JA, Gamble RJ, Link JS (2013) The relative impact of warming and removing top predators on the Northeast US large marine biotic community. Ecol Model 264: 157-168

Pauly D, Christensen V, Dalsgaard J, Froese R, Torres F Jr (1998) Fishing down marine food webs. Science 279: 860-863

Pikitch EK, Santora C, Babcock EA, Bakun A and others (2004) Ecosystem-based fishery management. Science 305:346-347

R Development Core Team (2010) R: a language and environment for statistical computing. R Foundation for Statistical Computing, Vienna

Rice JC (2000) Evaluating fishery impacts using metrics of community structure. ICES J Mar Sci 57:682-688

> Rice JC (2009) A generalization of the three-stage model for advice using the precautionary approach in fisheries, to apply broadly to ecosystem properties and pressures. ICES J Mar Sci 66:433-444

Rice JC, Rochet MJ (2005) A framework for selecting a suite

Editorial responsibility: Jake Rice,

Ottawa, Ontario, Canada of indicators for fisheries management. ICES J Mar Sci 62:516-527

Richter BD, Mathews R, Harrison DL, Wigington R (2003) Ecologically sustainable water management: managing river flows for ecological integrity. Ecol Appl 13:206-224

Rose GA (2005) On distributional responses of North Atlantic fish to climate change. ICES J Mar Sci 62:1360-1374

Sainsbury KJ, Punt AE, Smith ADM (2000) Design of operational management strategies for achieving fishery ecosystem objectives. ICES J Mar Sci 57:731-741

Samhouri JF, Levin PS, Ainsworth CH (2010) Identifying thresholds for ecosystem-based management. PLoS ONE 5:e8907

Samhouri JF, Lester SE, Selig ER, Halpern BS, Fogarty MJ, Longo C, McLeod KL (2012) Sea sick? Setting targets to assess ocean health and ecosystem services. Ecosphere 3:art41

Shackell NL, Bundy A, Nye JA, Link JS (2012) Common large-scale responses to climate and fishing across Northwest Atlantic ecosystems. ICES J Mar Sci 69:151-162

Shin YJ, Shannon LJ (2010) Using indicators for evaluating, comparing, and communicating the ecological status of exploited marine ecosystems. 1. The IndiSeas project. ICES J Mar Sci 67:686-691

Shin YJ, Bundy A, Shannon LJ, Simier M and others (2010) Can simple be useful and reliable? Using ecological indicators to represent and compare the states of marine ecosystems. ICES J Mar Sci 67:717-731

Smith TM, Reynolds RW, Peterson TC, Lawrimore J (2008) Improvements to NOAA's historical merged land-ocean surface temperature analysis (1880-2006). J Clim 21: 2283-2296

> Stenseth NC, Mysterud A, Ottersen G, Hurrell JW, Chan KS, Lima M (2002) Ecological effects of climate fluctuations. Science 297:1292-1296

Strang G (1991) Calculus, $1^{\text {st }}$ edn. Wellesley-Cambridge Press, Wellesley, MA

Taylor AH (1995) North-south shifts of the Gulf Stream and their climatic connection with the abundance of zooplankton in the UK and its surrounding seas. ICES J Mar Sci 52:711-721

Trenkel VM, Rochet MJ (2003) Performance of indicators derived from abundance estimates for detecting the impact of fishing on a fish community. Can J Fish Aquat Sci 60:67-85

Vinod HD, López-de-Lacalle J (2009) Maximum entropy bootstrap for time series: the meboot R package. J Stat Softw 29:1-19

Wood SN (2003) Thin plate regression splines. J R Stat Soc Ser B Stat Methodol 65:95-114

Wood SN (2004) Stable and efficient multiple smoothing parameter estimation for generalized additive models. J Am Statist Assoc 99:673-686

Wood SN, Augustin NH (2002) GAMs with integrated model selection using penalized regression splines and applications to environmental modelling. Ecol Model 157: $157-177$

Zuur A, Tuck I, Bailey N (2003) Dynamic factor analysis to estimate common trends in fisheries time series. Can $\mathrm{J}$ Fish Aquat Sci 60:542-552

Submitted: August 27, 2014; Accepted: December 17, 2014 Proofs received from author(s): January 19, 2015 